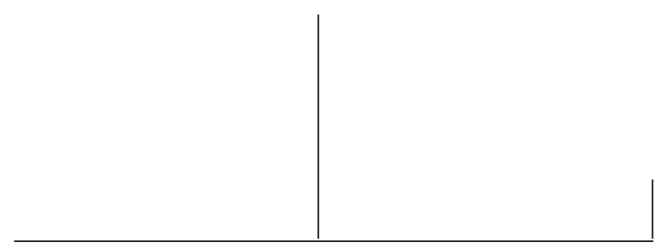

Rev. Latinoam. Psicopat. Fund., X, 3, 395-409

\title{
A vida no paraíso, a vida no inferno: a viagem longitudinal da melancolia
}

\author{
Manoel Tosta Berlinck \\ Regina Maria Guisard Gromann \\ Marciela Henckel \\ José Waldemar Thiesen Turna
}

O quadro melancólico apresenta bruscos movimentos longitudinais associados a uma profunda tristeza, alternados com atividades e afetos maníacos impossibilitando ao sujeito uma parada depressiva. Este artigo explora significados desses movimentos intrapsíquicos e estabelece relações com a depressão, o luto, a inibição, o humor e o sonho.

Palavras-chave: Melancolia, depressão, luto, inibição, psicopatologia fundamental 


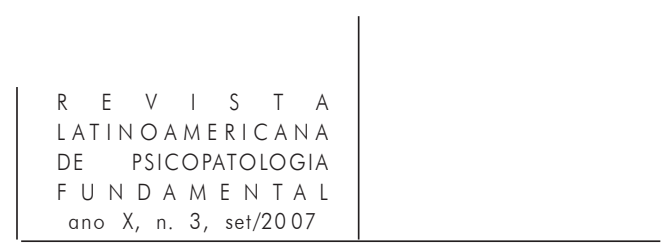

Subamos!
Subamos acima
Subamos além, subamos
Acima do além, subamos!
Com a posse física dos braços
Inelutavelmente galgaremos
O grande mar de estrelas
Através de milênios de luz.
Subamos!
Como dois atletas
O rosto petrificado
Subamos acima
Com a posse física dos braços
E os músculos desmesurados
Na calma convulsa da ascensão
$\ldots$
E quando
Lá, acima
Mlém, mais longe que acima do além
Adiante do véu de Betelgeuse
Depois do país de Altair
Sobre o cérebro de Deus
Num último impulso
Libertados do espírito
Despojados da carne
Nós nos possuiremos.
E morreremos
IMENSAMENTE ALTo
Minícius de Moraes, Os acrobatas)

O quadro melancólico sugere bruscos movimentos longitudinais associados a uma profunda tristeza, alternados com atividades e afetos maníacos impossibilitando o sujeito de uma parada depressiva. Como num trânsito dentro de um elevador frenético, o sujeito se desloca do mais alto para o mais baixo humor sem conseguir um pouso possível para o pensamento. Uma condição para a mudança de direção parece se encontrar na hipótese segundo a qual, capturado nesse elevador, o sujeito procurasse um pouso em algum lugar e diante de um 


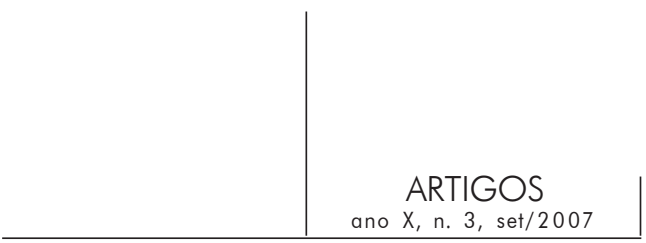

andar necessitasse fazer sua entrada: um limiar possível de realização de um luto. O estado depressivo, com a constituição de uma organização narcísica do vazio, é a parada possível para uma futura brotação, a depressividade.

Alguns elementos são necessários para a ação superegóica na melancolia, sua sombra recaindo sobre o ego, mortificando-o. Uma delas é a ação traumática e intoxicante produzida no corpo. Cotidianamente, o humano é atravessado por esta ação corrosiva, traumática, sendo necessária, portanto, permanente ação traumatolítica (Ferenczi, 1992).

Um outro aspecto a se considerar é a questão do tempo enquanto eixo latitudinal (passado, presente, futuro) ausente no movimento melancólico. O fenômeno onírico remete a uma intersecção relevante nesta inclusão do tempo, condensando aspectos múltiplos deste eixo temporal. Nesta medida, incluir o eixo latitudinal acena para a transformação de um acontecimento psíquico através do tempo, convertendo-o em história. $\mathrm{O}$ estado depressivo possibilita um vazio continente, passível de brotações oníricas e lembranças.

O trabalho do luto, a subjetivação de uma perda, a depressividade e o trabalho onírico constituem algumas possibilidades de direção de tratamento para situações clínicas nas quais o sujeito se encontra dominado por um funcionamento psíquico melancólico-maníaco.

"A vida é um tobogã”, comenta um paciente, completando em seguida: "o meu só tem descida".

Ainda jovem, com 22 anos, assumiu a administração de três filiais de uma empresa. Apesar do medo que o acompanhava diante das novidades, não recuava, fazia delas um desafio e tinha facilidade em aprender rápido. Com o passar dos anos, no "auge" de sua vida profissional, econômica e afetiva, percebeu desmoronar suas conquistas quando foi afetado por crise de pânico.

Desde então seu mundo passou a ter limites bem demarcados, reduzindo consideravelmente a dimensão na qual poderia se deslocar. Em outras palavras, a mobilidade psíquica só ocorria num espaço muito reduzido. Um eu angustiado pelo achatamento de um supereu avassalador, um outro "sempre me passava a perna".

Não é nossa intenção apresentar comentários sobre diferentes possibilidades de diagnóstico, o qual somente se define, na melhor das hipóteses, ao longo do tratamento. Interessa, entretanto, observar o funcionamento psíquico predominante. Quando o paciente diz que a vida é um tobogã aponta para uma dinâmica psíquica longitudinal, vertical, em que a descida impulsiona um movimento de subida, apesar de, no seu caso, só vislumbrar a queda. É assim o deslocamento melancólico (Binswanger, 2002). Neste sentido o medo sempre atuante pode ser a forma encontrada para evitar a queda sem limites no abismo, um fracasso menos radical. O medo segura o movimento e evita o risco. 


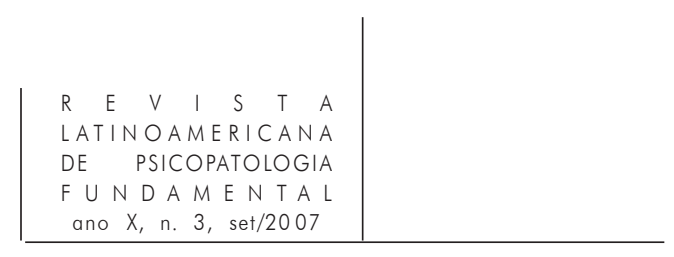

Enquanto na melancolia o sujeito é tomado por um movimento vertical à deriva, mergulhando no abismo para daí emergir, com o medo o sujeito constrói uma espécie de mini-tobogã, evitando transformar a descida numa queda livre. Ele simplesmente vai parando aos poucos ao perceber o quanto o abismo está próximo e, neste sentido, evita o risco de se ferir.

Há, aqui, nuanças da inibição enquanto parada, interrupção de movimento. $\mathrm{Na}$ melancolia propriamente falando, a tristeza afeta a vontade, cria a obsessão com a ordem, torna o sujeito covarde em dizer o que pensa, podendo levar até ao delírio de negação observado por Cotard (1998). A paralisia da vontade, provocada pela tristeza, sugere a Versagung - comumente traduzida por frustração. Entretanto, seu sentido estende-se para além quando o sujeito, frustrado por não encontrar a água para saciar sua sede, perde a vontade de beber. Na Versagung, mais que uma frustração, ocorre uma perda da vontade, ocorre o estancamento da libido, uma espécie de "brochamento" provocando adoecimento. Assim, ocorre aqui uma inibição mais radical.

A covardia é forma de não correr risco e a tristeza melancólica é justamente o afeto da impossibilidade de correr risco. Sua natureza crítica impossibilita qualquer movimento, ação. Por isso, trata-se de uma inibição mais radical, ou talvez, como qualifica Freud (1926), uma inibição generalizada.

Culpa, vergonha e arrependimento, escravizam o sujeito, fazendo do supereu seu senhor, severo e cruel. Seu funcionando psíquico no eixo vertical oscila entre o ideal e o fracasso. O eixo horizontal, da historicidade, articulando passado, presente e futuro não existe. A tristeza no melancólico é um afeto que tem íntima relação com o presente e o futuro, na medida em que não há presente nem futuro. Nesta dinâmica, o futuro sofre um processo de fagotização, ${ }^{1}$ mantendo o sujeito no gozo de um passado ideal ou fracassado.

\section{O humor, a tristeza e a depressividade}

O humor é vida. Qualquer manifestação deste afeto atesta a constituição de um corpo vivo. É nele, enquanto espaço e terreno corporal, e a partir dele, enquanto força, que encontraremos o apoio onde irá vigorar a operação necessária para, na sujeição ao Pai morto, se operar um além da situação vigente, a possibilidade de transcendência do sujeito.

1. Fagocitose - ingestão e destruição de uma partícula sólida ou de um microrganismo por uma célula. In: Ferreira, Aurélio Buarque de Holanda e J. E. M. M. Novo dicionário Aurélio da Lingua Portuguesa. 


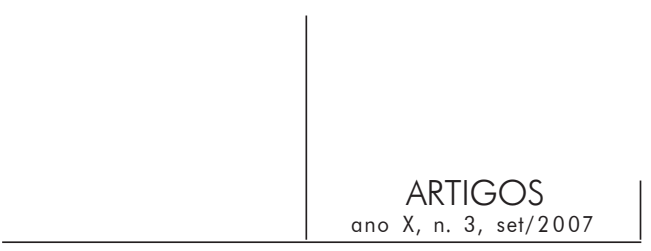

A operação do humor se associa à defesa da castração proposta por Freud como a Verdrängung, ou melhor, o desalojamento.

A partir do humor é possível pensar e reconhecer algumas diferenças entre tristeza e depressão. Atravessando a melancolia e a mania, passando pela depressividade e questionando a "segunda consciência", exame feito pela mesma para dar sentido àquilo que foi - aparentemente - sem sentido, chega-se à construção da historicidade do sujeito.

Pode-se, então, pensar na origem do humor? Em que momento este afeto pode ser identificado como próprio de um ser?

O infans inicia sua trajetória no mundo das erogenizações encontrando em sua mãe o primeiro objeto de interferência na carne. Marcado por sua insuficiência, depende dela para, além de sobreviver pelo que lhe é oferecido pela boca, encontrar o sustento necessário investido por uma libidinização dos objetos. Os objetos farão parte desta rede libidinizada na medida em que a mãe possa oferecer um mundo para ser provado pelo infans.

O lugar do pai não ocupa unicamente o estatuto humano. A função "Pai" serve de apoio para a instalação de uma barreira ante o gozo materno. Esta expressão, por sua vez, é utilizada para explicitar aquilo a ser barrado. Este corte opera ante o poder desse primeiro objeto, o poder-mãe, como um circuito avassalador de oferta solicitando a instalação de uma comporta iniciadora do recorte libidinizador das zonas corporais (Hardt, 2005).

Surge, então, a possibilidade do infans recusar, interromper, diferenciar o que é da "mãe" do que não é seu; UM pai lhe informa justamente isso, o que não é mais seu.

Daí as primitivas instalações, primeiras constelações do desejo que irá assegurar a saúde de um corpo. Não está no gozo essa condição saudável, o gozo se orienta pela desmedida, excesso ou falta, que marca o objeto em seu lugar de resto de uma operação que organiza uma estética. Estética do fantasma originário deste corpo, desalojamento que tem como resultante da equação ternária edípica a produção de um resto, que será marcado enquanto resquício a ser recuperado.

Estética originalmente orientada pela oralidade, poderá ter ou não condições de barganhar com este traço; constituição futuramente marcada pela equação do que Lacan nomeou de "objeto a" com o gozo imperativo superegóico - este resto certamente virá a se constituir enquanto objeto pela moção das duas condições simultaneamente.

É em relação a essa futura "barganha" que o ego se apoiará para poder ou não lidar com estes resquícios, tão mortais quanto necessários para orientar o porvir deste sujeito ou condená-lo a uma fixação humoral em sua história. 


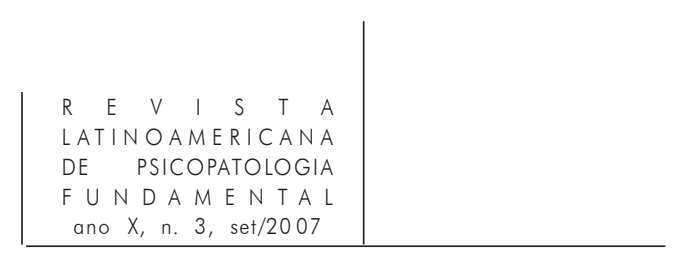

Isto que ainda não lhe pertence (e que inteiramente nunca terá) é o que deverá, arduamente, transformar em seu: uma consciência de si.

Que ainda não lhe pertença faz parte de todo um intrincado processo, mas é neste intervalo aflitivo de intervenções difusas entre seu desejo e os objetos que o circunda, seu acesso ou não aos mesmos, que passa a constituir o que mais tarde poderemos escutar como a língua no corpo, o que Lacan designou como "fala-ser", identidade que estará ligada à história do sujeito.

Porém, antes dessa língua falada ocorre incidência de uma língua do corpo. Sem relação clara de instalação, sem precisar sua origem, passamos a compartilhar com os movimentos do bebê, movimentos que se confundem com os nossos. Como observadores constituímos e somos constituídos em cenas que passam a responder a uma encenação que nos orienta sobre nossa origem. Atravessados por um enigmático jogo de atuações que nunca mais poderá ser desvelado desde sua incidência original (a fantasia original), temos aí a marca indelével de um desalojamento que passa a enviar constantemente este corpo para outro lugar, um lugar outro, marcado pelas relações objetais fundamentais e onde um eu poderá aos poucos se constituir enquanto próprio, historicizando-se.

Esta história pessoal passa a circular por este corpo enquanto humor.

O humor é cíclico desde sua entrada no corpo, ele é e pede alternância. Para se constituir deverá apresentar este trabalho contínuo, para além do sujeito e além de sua intenção, como moto-contínuo que se manifestará sem parar. Daí a importância da mania e da depressão para um corpo.

A mania é força de gozo, "caos", potência sem direção que poderá ser articulada, direcionada para um fim. Para o infans e seu corpo, a mania virá mais tarde a constituir um modo de defesa bastante importante enquanto força vital. O "riso", que se propõe enquanto modo bastante primitivo de defesa ante a angústia, tem aí originária força.

Octave Mannoni (1992) descreve o riso como "reação a algo negativo, hostil, assustador ou angustiante (...). Há sempre um meio - ainda quando as coisas vão mal e não se pode fazer nada - de recorrer ao riso, e esse recurso desesperado chama-se humor" (p. 135). Se a mania constitui motor do gozo, é necessário manejar sua força em prol do humor, constituindo assim qualidade de defesa para o corpo.

Mas o humor pode ser maníaco, pode vagar sem permitir qualquer reflexividade, impedindo a ocupação do sujeito consigo mesmo. Por mais que o sujeito adentrado neste modo de operação maníaco tente realmente ocupar todos os espaços de sua vida psíquica com sua ativação, nunca poderá recorrer a este modo enquanto um empreendedor.

Como diz Piera Aulagnier (1991): 


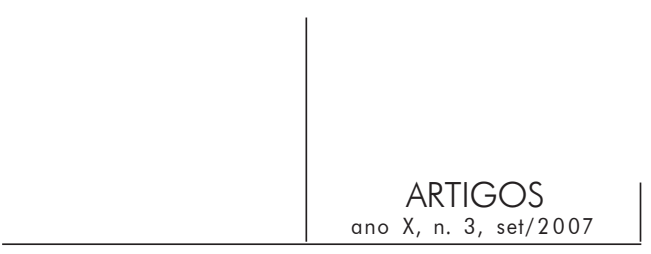

O maníaco, escutem-no, é aquele que trepa melhor que os outros, que come mais do que todos, que excreta formidavelmente etc., mas, de fato, ele não tem corpo. Do seu corpo, ele nos fala como de um agregado de órgãos que circundam um vazio: o que clama o maníaco é que ele possui tudo, porque não deseja nada. (p. 70)

Já a depressão está ligada à manifestação da vida. Ela se liga a um estado próprio da existência enquanto regulador do humor, ou seja, ela serve para o humano enquanto um estado que possa conduzi-lo, quando o corpo sinaliza necessário a um afastamento, recolhimento no intuito de recompor suas forças e poder, em tempo (e nunca sem ele) de retornar à sua história.

Este momento de retorno é a depressividade, um awakenning um despertar no qual o sujeito reconhece o mundo e suas nuanças e passa a dar sentido ao que viveu sendo afetado e tomado por uma força que modifica seu estado (Berlinck e Fédida, 2000; Berlinck, 2000).

O humor não pára, a menos que esteja doente ou dormente. Esta dormência às vezes pode ser longa, como o sono descrito no livro Tempo de despertar, de Oliver Sacks (1997) no qual é relatada a condição de pacientes traumatizados que, em sua depressão, se recolhem a um estado de sono por muitos anos.

$\mathrm{Na}$ depressão é necessário que o corpo possua um "a mais" (instância reguladora desse corpo) que possa introduzir este "a menos" (condições para deprimir-se). Ela é, pois, a qualidade de sobrevivência frente à ameaça de se ver aniquilado ante a angústia insuportável de ter de lidar com o objeto, não produzindo outra saída a não ser o desligamento radical. Este processo pode estar associado ao mecanismo regulador do sono ou às formas mais profundas de depressão.

Entretanto, a depressão passa e sua saída é a depressividade. Esta reside na condição de nosso corpo poder se representar no futuro, representação esta contida no sonho. O futuro é uma invenção a partir da "língua morta"; sendo uma construção lingüística - uma amarração entre os três registros Real, Simbólico e Imaginário. Ele se refere ao passado, à memória, aos mortos simbolizados e presentes em nosso corpo (a língua morta) e sua articulação com o futuro (a língua viva).

O sonho, enquanto construção lingüística, tem a característica de não permitir o acesso a essa construção nem mesmo ao sonhador, pois sua formação se dá na desvinculação do desejo com o passado (já que estamos definitivamente desalojados do modo de constituição do desejo). O importante é que em seu despertar o sonhador deverá poder vincular seu passado a uma interpretação onírica, dando assim estatuto de atualidade a seu sonho, à sua consciência e à sua história, conduzindo à possibilidade de vislumbrar um porvir para seu destino. 


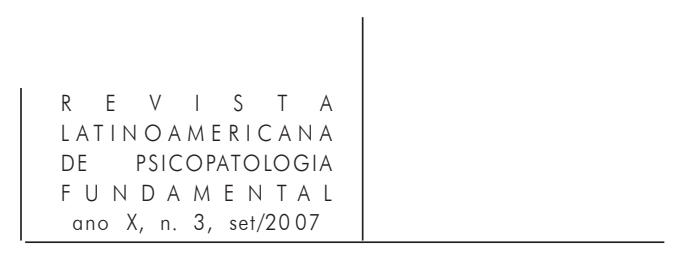

O humor propõe a criação de um "espaço psíquico" visando orientar a posição do corpo no espaço e no tempo, ou seja, o humor contribui de modo decisivo para a orientação de um sujeito em sua historicidade. Não há contexto onde o humor não interfira enquanto traço contribuindo para lançar o corpo em direção a um porvir empreendedor ou fixá-lo em um passado inapelável.

Na comunicabilidade do humor, há um endereçar algo ao Outro, convocando uma resposta perante o Outro, ou seja, o sujeito marca e é marcado pelo humor circundante.

O humor pode elaborar um plano horizontal, latitudinal que traça a historicidade do sujeito, história nunca desvinculada do humor. Incidindo verticalmente sobre essa reta surgem os traços que invadem o humor proporcionando um modo de manifestação pelo Ideal ou pelo fracasso.

A identidade de um sujeito, sua existência, apóiam-se nesse eixo Idealfracasso, porém apoiar-se é diferente de fixar-se. Quando isso ocorre há um estancamento no eixo regulando o modo do sujeito se portar perante a vida: sua existência se imobiliza.

Porém, é bom lembrar que o movimento vertical é ditado pelo repetitivo fracasso em relação ao ideal, principal manifestação na melancolia, uma impossibilidade do porvir alcançar a consciência. O sujeito se desloca no espaço psíquico da verticalidade, espaço dos ideais e dos fracassos. Verticalidade que não encontra na horizontalidade histórica qualquer apoio para vislumbrar um horizonte, só é possível se enxergar de cima para baixo, da vertigem do alto ao fosso do abismo.

Em sua relação direta com o superego, o ego, apequenado por esta instância, incide para apagar a história e fazer operar o ideal e o fracasso: mania e melancolia enquanto eixo sintomático próprio das neuroses narcísicas propostas por Freud (1917).

Surge, então, a vergonha vindo para "travar" o sujeito. Diferentemente da depressão, a melancolia impõe uma parada que não se refere à vida, mas sim à morte. O sujeito, siderado por sua condição de fracassado, freqüentemente envergonhado por se encontrar tão distante de seu ideal, fixa-se no tempo e no espaço, encontrando um lugar povoado de excessos. Em sua "mais valia", o objeto pequeno $a$, objeto causa do desejo, não suporta outra coisa a não ser o gozo associado ao estado de morte, um excesso mortífero orientando o modo de seu humor.

A vergonha é o afeto a respeito do fracasso ante o ideal, e o que virá para moldar a fácies deste sujeito será a tristeza (Di Vettimo, 2006). Tristeza ligada a esse fracasso tornando-se mortal e podendo se manter muito ativa, pois está, agora, intimamente ligada ao Ideal. Ocorre aqui uma diferença significativa entre 


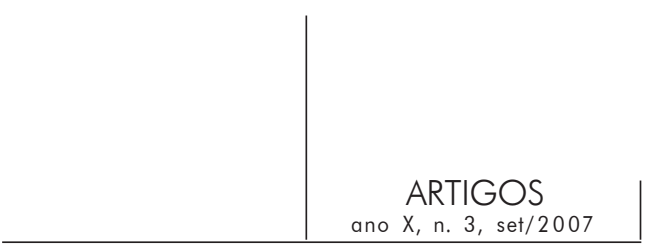

este modo melancólico em sua conexão com a morte e o estado de depressão e seu vital recolhimento (Berlinck e Fédida, 2000).

A tristeza sustenta uma dinâmica vinculada ao ter e não ao ser, pois na melancolia não há trabalho de dar sentido à existência, incidindo de modo contundente o trabalho de crítica. Encontra-se aí, voltando à constituição do desalojamento do ser, uma operação não mais tamponada, devendo ficar afastada do sujeito, o desalojamento em questão passa a devorá-lo. Observa-se isso clinicamente no apagamento de sentido na memória desses sujeitos, fazendo-os se aproximarem da esquizofrenia. Como nesta, o melancólico não encontra sentido em sua existência.

O fracasso se torna um fetiche do ter, ele é agora o outro lado da moeda do gozo incidindo na sintomatologia melancólica, e como não há um trabalho de sentido à existência, o único sentido encontrado por essa consciência será o fracasso, fracasso de uma existência.

Como propor uma saída para esta existência humana, triste, envergonhada e inibida, tingida de inveja?

Propor uma saída não equivale pensar em uma escapatória. Há que se propor um modo de "acordo" entre o ego e as demais forças que encarceram o corpo em sua condição triste, envergonhada e inibida, centrada no eixo vertical Idealfracasso.

Se na melancolia não se encontra presente o porvir é porque o sujeito assim acometido se desloca no espaço psíquico da verticalidade, espaço dos ideais e do fracasso, já que este impõe a visada ao melancólico. Daí seu horror ao passado, sua impotência centrada na memória.

$\mathrm{Na}$ melancolia o futuro é vivido como impossível, como fracasso, como dejeto. Um paciente narra o seguinte sonho: "sonhei com um cocô. É só o que me lembro deste sonho". Aqui, o objeto do desejo é corpo enquanto dejeto.

Se não estivermos confrontados com os casos que não oferecem qualquer saída para sua condição, onde observamos, impotentes, os fracassos, na tentativa erótica da transferência, casos que irremediavelmente encontrarão antes da morte a agonia insuportável da angústia nas relações de objeto, sujeitos acometidos por uma "síndrome de Cotard", por exemplo, devemos pensar sobre as condições de sonhar, condições de viver o luto do objeto perdido de modo que daí finalmente se opere um desalojamento. Para isso será exigido do terapeuta um trabalho erótico no corpo de seu paciente, trabalho visando re-situar a morte e o assassinato de seu objeto na história do paciente. "Só essa morte outorga estatuto de dom ao objeto que foi arrancado. Só ela o transforma num objeto de sacrifício" (Allouch, 2004, p. 15).

Oferecer algo que se reconstrua, um remanejar na constelação histórica permitindo ao terapeuta encontrar as brechas que podem oferecer outro modo de 


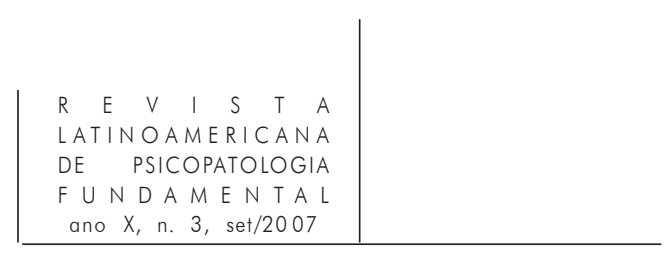

constituição especular, talvez seja a direção do tratamento a ser dada nesses casos. Direção esta servindo para o paciente olhar sua memória com um olho para o porvir. O "cuidar de si" é a articulação da memória com o porvir, e isso se torna uma arte enquanto trabalho. Tarefa artística entre o sujeito e seus feitos, dominar o que se é em face do que se passa, lançando assim as bases para um porvir que nunca será (Foucault, 2004).

O humor é operado com transgressões, não devendo ser confundido com ironia - recurso melancólico - ou com atos subversivos, saída muitas vezes utilizada nas neuroses obsessivas através de suas justificativas, desculpas, paralisações inúteis a outra coisa que não uma construção abrigada, um bunker defensivo que não propõe a menor saída do sintoma operante.

A transgressão utiliza criatividade e ousadia, ou seja, um laço que convoca o Pai, que o desafia. A aposta em seu ato utilizando o passado como referência para a construção de um futuro, porvir que restitui ou outorga uma singularidade ao sujeito, separa-o de sua vergonha, e permite o trânsito menos fixado a seus ideais de fracasso.

Restaurar o humor é dever de toda terapêutica voltada para o vivo. Nas palavras de Foucault (2004),

... o cuidado de si é uma espécie de aguilhão que deve ser implantado na carne dos homens, cravado na sua existência, e constitui um princípio de agitação, um princípio de movimento, um princípio de permanente inquietude no curso da existência. (p. 11)

\title{
A estética onírica como encruzilhada na melancolia
}

\author{
O abismo não passaria de um aniquilamento \\ oportuno? Não me seria difícil nele ler não \\ um repouso, mas uma emoção. Mascaro meu \\ luto sob uma fuga; diluo-me, desvaneço-me \\ para escapar a esta compacidade, a esta \\ saturação que faz de mim um sujeito \\ responsável: saio: é o êxtase.
}

(Roland Barthes, Fragmentos de um discurso amoroso)

Geréz-Ambertín (2006) menciona

... se o sonho e seu texto - como modelo das formaç̃es do inconsciente - "é realização de desejo", a instância superegóica, em contrapartida, introduz um limite, pois sonhos autopunitivos, pesadelos e "necessidade de castigo" - que 


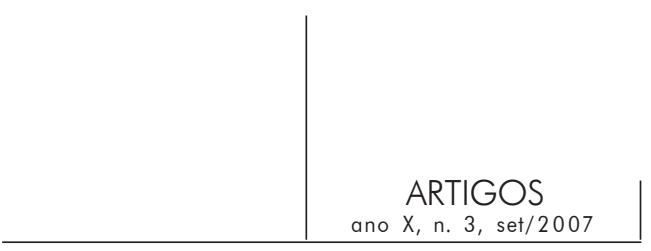

configuram parte da constelação superegóica - são a exceção daquela realização. (p. 47-8)

E continua: "Podemos afirmar, então, que tanto na teoria de Freud quanto na de Lacan, o supereu dá conta da versão intrusiva e não regulada - como corpo estranho e traumático - do inconsciente que obriga o sujeito" (ibid.).

Ferenczi (1934) em seu texto "Reflexões sobre o trauma" recoloca no sonho mais uma função: sua ação traumatolítica. Neste sentido trauma e elaboração psíquica estariam intimamente ligados (cf. Gromann, 2002). Duas saídas são mencionadas por Ferenczi: em primeiro lugar, o afastamento da causa do distúrbio, uma reação aloplástica, ou seja, a transformação desse distúrbio; em segundo, a capacidade de produção de imagens de representação, produzindo uma expectativa, tornando o sujeito capaz de tolerar o desprazer, não senti-lo ou sentilo menos. Essa espera estaria vinculada à capacidade de criação, na fantasia de representações que possibilitariam a expectativa de um prazer, "um antídoto à dor", um certo amortecimento que capacitaria o sujeito a viver a dor com menos desorientação. Deste modo, o pesadelo melancólico é o fracasso do sonho elaborativo, pois a angústia não podendo ser sustentada pelo ego, desperta o sujeito afastando-o dessa condição. Já os sonhos autopunitivos seriam a primeira das saídas do frenesi alternante de humor.

As várias camadas apresentadas no sonho, seu "umbigo" como nos diz Freud, abarca o tempo, a vida e a morte. Se por um lado o inconsciente se apresenta como atemporal, a estética onírica revela o drama sexual infantil, com elementos do presente e compondo um tema visionário: o sonho é, assim, um observatório, um emblema da configuração psíquica do sujeito, pois o sonho narrado no processo terapêutico traz também o porvir. A estética onírica possibilita movimentos psíquicos num outro eixo, podendo ser uma encruzilhada encontrada pelo sujeito para viver a perda e o luto.

Trabalho de luto e trabalho de sonho. Integração e perlaboração ${ }^{2}$

O termo Durcharbeitung utilizado por Freud, refere-se a uma espécie de elaboração supondo um atravessamento, uma tarefa prolongada, pois o prefixo Durch significa atravessar, entrar e sair, através de (percorrer ou atravessar uma tarefa do início ao fim). É o que acontece no trabalho do luto.

Esta expressão indica que, por meio do trabalho, processa-se uma mudança. O trabalho de ligação é empreendido pelo aparelho psíquico tanto no trabalho de

2. Parte modificada da dissertação de mestrado de Gromann, R. M. G. Corpo e subjetividade: a função do sonho na evolução psíquica. 


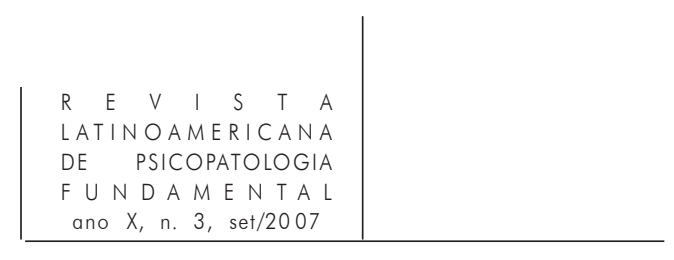

luto quanto no trabalho do sonho. Este, por sua vez, é denominado Umarbeitung, referindo-se a um trabalho de transfigurar-reformar, dar nova forma, distorcer, remodelar.

O trabalho do sonho diz respeito à transformação realizada pela deformação onírica dos pensamentos oníricos de vigília, surgidos a partir de restos diurnos, que em seu estado natural não poderiam entrar na consciência por serem produtos de desejos proibidos infantis. A deformação estaria a serviço de uma formação de compromisso para que as forças psíquicas possam entrar em acordo e para que os conteúdos possam ter passe relativamente livres. Ora, sabe-se que essa é uma operação que envolve mecanismos de camuflagem do desejo, transformando matéria-prima em produto onírico. É um processo sofisticado exigindo trabalho e maturidade do aparelho psíquico para poder ser acionado.

Da mesma forma, o trabalho do luto envolve mecanismos exigindo igualmente maturidade e trabalho. O termo "elaboração psíquica" também é utilizado como sinônimo de perlaboração, e diz respeito a diversos contextos de trabalho realizado pelo aparelho psíquico, com a finalidade de lidar com as excitações e com o acúmulo destas, necessitando serem ligadas em cadeias associativas para que possam ser elaboradas. Nesse sentido, ligar o excesso de energia que chega à psique seria o labor fundamental do sujeito. Paradoxalmente, no processo de luto há inicialmente um trabalho de desvinculação realizado pelo sujeito numa situação de recuo narcísico do objeto perdido, para posteriormente ser realizada uma nova ligação com os objetos vivos.

Ora, sabe-se que a atmosfera psíquica do enlutado é de morte; algo como se o sujeito estivesse morto, como o morto perdido. Algo morre dentro dele. A tarefa psíquica a que fica submetido, durante o trabalho do luto, é a presença do morto: as lembranças, o reviver a dor da perda, até que, ao se desvincular desta relação retoma outras ligações, agora com objetos vivos. Na verdade, é uma operação trabalhosa e dolorida, pois remete à questão de ter que processar as ligações com o morto e aceitar estar vivo.

Em algumas circunstâncias, porém, como a de uma criança pequena, o trabalho de luto pode ficar prejudicado pela incipiência do aparelho psíquico, tornando-se um acontecimento traumático necessitando ser elaborado mais tarde. Nessa medida, os ecos desta perda acompanharão o sujeito no decorrer de sua vida, influenciando os modos de elaboração em torno dos quais acabam por ser repetitivos e sob a égide da atuação.

O trauma revisitado reivindica ligações até então impossibilitadas de se realizarem. Estamos no terreno dos investimentos pulsionais e de tudo aquilo que se refere ao que Freud relatou quando descreveu a angústia automática e a angústia sinal. Desinvestir um objeto perdido, morto, é um trabalho penoso 


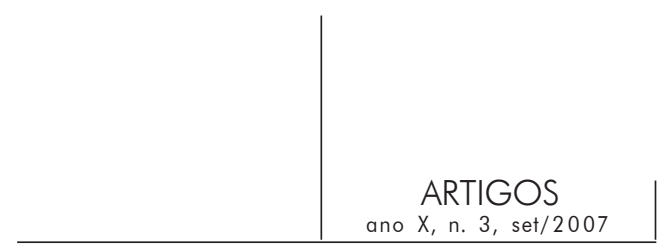

necessitando de um lugar propício. No início, esse lugar não é reconhecido como interno. Há certa transicionalidade a ser ultrapassada, e, nessa medida, é vivida pela dor, na carne do corpo. Surge, assim, a necessidade de o sujeito dar sentido às impressões traumatizantes, por meio da perlaboração pelo sonho, ao reviver o acontecimento traumático, permitindo que na dimensão do sonho e da análise realizada pela dupla analítica, transforme o acontecimento traumático em narração de experiência. A possibilidade de sonhar com o acontecimento traumático já é a condição de estar incluído na cadeia associativa, e com isso fazer parte dos conflitos intrapsíquicos. Outras vezes, por incipiência psíquica, o fato traumático torna-se um fantasma perseguindo o sujeito, como um pesadelo melancólico, empedernido, o qual precisa ser incluído na cadeia associativa para integrar-se ao processo psíquico.

Na melancolia o sujeito se identifica com o objeto morto, paralisando toda possibilidade de trabalho de luto. Nesses sujeitos, o trabalho de sonho fica suspenso, incorrendo em situações que podem levar ao delírio ou até aos sintomas somáticos, caracterizando um sonambular em vida como um morto, sublinhando o quanto esses dois trabalhos levam o sujeito a integrações relevantes em seu processo de evolução psíquica.

\section{Referências}

Allouch, J. Erótica do luto no tempo da morte seca. Rio de Janeiro: Companhia de Freud, 2004.

Aulagnier, P. Observações sobre a estrutura psicótica. In: Katz, C. S. (org.). Psicose: uma leitura psicanalítica. São Paulo: Escuta, 1991.

Barthes, R. (1977). Fragmentos de um discurso amoroso. São Paulo: Martins Fontes, 2003, p. 6.

Berlinck, M. T. e FÉdida, P. A clínica da depressão: questões atuais. Revista Latinoamericana de Psicopatologia Fundamental, v. III, n. 2, p. 9-25, jun./2000.

Berlinck, M. T. Psicopatologia fundamental. São Paulo: Escuta, 2000.

Binswanger, L. O sonho e a existência. Natureza Humana. Revista Internacional de Filosofia e Práticas Psicoterápicas, v. 4, n. 2, p. 417-52, jul.-dez./2002.

Cotard, J. Do delírio das negações - 1882. Revista Latinoamericana de Psicopatologia Fundamental, v. I, n. 4, p. 156-77, dez./1998.

Di Vettimo, D. S. Elementos para uma teoria da vergonha na psicose. Revista Latinoamericana de Psicopatologia Fundamental, v. IX, n. 3, p. 496-507, set./2006. 


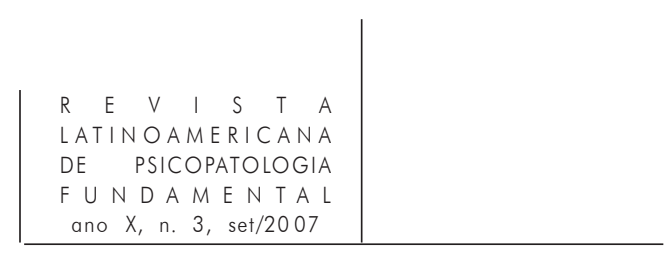

Ferenczi, S. (1934). Reflexões sobre o trauma. In: Obras completas. Psicanálise IV. São Paulo: Martins Fontes, 1992.

Ferreira, A. B. H. e J. E. M. M. Novo dicionário Aurélio da Língua Portuguesa. Rio de Janeiro: Nova Fronteira, 1986.

Foucault, M. A hermenêutica do sujeito. São Paulo: Martins Fontes, 2004.

Freud, S. (1917). Luto e melancolia. In: Edição Standard Brasileira das Obras Psicológicas Completas de Sigmund Freud. Rio de Janeiro: Imago, 1976. v. XIV.

(1926). Inibições, sintomas e ansiedade. In: Edição Standard Brasileira das Obras Psicológicas Completas de Sigmund Freud. Rio de Janeiro: Imago, 1976. v. XX.

Gerez-Ambertín, M. G. Imperativos do supereu: testemunhos clínicos. São Paulo: Escuta, 2006.

Gromann, R. M. G. Corpo e subjetividade: a função do sonho na evolução psíquica. 2002. 130p. Dissertação (Mestrado em Psicologia Clínica), Pontifícia Universidade Católica de São Paulo.

HARDT, B. O nascimento de uma mãe e os princípios de seu poder: contribuições para a psicopatologia fundamental. 2005. 111p. Dissertação (Mestrado em Psicologia Clínica), Pontifícia Universidade Católica de São Paulo.

Henckel, M. Quando o sofrimento na infância é atravessado pela inibição: contribuições para uma Psicopatologia Fundamental. 2002. 148p. Dissertação (Mestrado em Psicologia Clínica). Pontifícia Universidade Católica de São Paulo.

Mannoni, O. O riso. In: Um espanto tão intenso. Rio de Janeiro: Campus, 1992.

Moraes, V. de. Os acrobatas. In: Poesia completa e prosa: o encontro do cotidiano. Rio de Janeiro: Nova Aguilar, 1998.

SACKs, O. Tempo de despertar. São Paulo: Companhia das Letras, 1997.

\section{Resumos}

El cuadro de la melancolía presenta bruscos movimientos longitudinales asociados a una profunda tristeza, alternados con actividades y afectos maníacos imposibilitando al sujeto una parada depresiva. Este artículo explora significados de esos movimientos intra-psíquicos y establece relaciones con la depresión, el luto, la inhibición, el humor y el sueño.

Palabras claves: Melancolía, depresión, luto, inhibición 


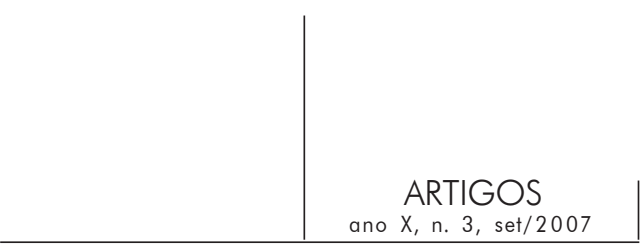

Le cadre mélancolique présente de brusques mouvements longitudinaux associés à une profonde tristesse, alternés d'activités et d'affects maniaques, rendant impossible au sujet un arrêt dépressif. Cet article porte sur les sens de ces mouvements intrapsychiques et établit des rapports entre la dépression, le deuil, l'inhibition, l'humeur et les rêves.

Mots-clés: Mélancolie, dépression, deuil, inhibition, psychopathologie fondamentale

The condition of melancholia presents abrupt longitudinal movements involving deep sadness, alternating with maniac activities and affects, with the result that the subject is unable to maintain a depressive position. This article explores meanings of these intrapsychic movements and establishes relationships with depression, mourning, inhibition, humor and dreams.

Key words: Melancholia, depression, mourning, inhibition, fundamental psychopathology

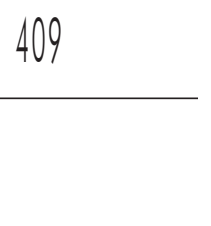

Versão inicial recebida em fevereiro de 2007

Versão revisada recebida em abril de 2007 